\title{
JUSTICIA Y HONRADEZ DEL GOBIERNO DE SANCHO PANZA
}

\author{
Lúdovik Osterc
}

La situación y el momento histórico que le tocó vivir a Cervantes, se caracterizaban por una grave crisis económica, social, politica y moral. Fue la época de Felipe II y su hijo, Felipe III, época del auge y la decadencia del imperio español. Sobre todo, bajo el cetro del segundo de los dos reyes la Hacienda estaba agotada, las arcas del erario vacías, la industria y el comercio agonizaban, el Estado andeudado y perdido el crédito. La agricultura estaba arruinada. Una exigua minoría, integrada por la nobleza con el rey a la cabeza, y el alto clero, poseía prácticamenta toda la tierra nacional, bañandose en un lujo indescriptible, en tanto que la mayoría del pueblo estaba sumida en la más pavorosa miseria. La sociedad española formaba una pirámide parasitaria, donde por el sistema de rentas sobre los empréstitos públicos y privados, un solo labrador debía alimentar a treinta productores.

La moral social, ante todo, la de las clases privilegiadas estaba por los suelos. Todo se vendía y todo se compraba: los cargos, los oficios, los favores, la justicia, los obispados, las indulgencias y hasta los sacramentos. La mentira, la hipocresía, el fraude, el peculdo y el robo se han convertido en el mismo sistema de gobierno.

La patria del gran novelista estaba envuelta en una atmósfera de represión sin precedentes dominada por la todopoderosa Inquisición que perseguía y quemaba en las hogueras, no sólo a los erasmistas y protestantes sino también a los más ingenuos disidentes. El propio Felipe II inauguró su reinado con dos autos de fe en Valladolid, en 1559.

Tal es el mundo que rodea a Cervantes durante su vida. Esta constituye algo único y fuera de lo imaginable que ejercerá un poderoso influjo en la formación de sus ideas sociales, políticas, morales y literarias. Ella refleja a la España misma y sus grandes problemas, pues nuestro autor ha sido víctima de ellos: ha sido condenado, desterrado, camarero, soldado, mutilado, cautivo, esclavo, excomulgado, pretendiente de Américas, quebrado y presidiario. Su biografía no es más que una novela de caballerías de la que a cada paso y aventura saliera mal parado. Abandonado, viviendo de limosnas más o menos disimuladas, combatido, con la ingratitud de la monarquía absolutista que regía los destinos de su patria, por la que tanto había sufrido, tras la mayor parte de sus años pródigos en adversidades y desgracias, cautiverios y cárceles, incomprensiones e injusticias, con su poderosa mente abarca la triste realidad y la plasma en el papel con su genial pluma. Así nace el QUIJOTE, el libro más grandioso que jamás se ha escrito. En 
él somete a una tremenda sátira a las clases dominantes de España, en particular, y a través de ellas, a las clases dirigentes, en general. Al propio tiempo, contrapone al podrido mundo feudal-eclesiástico una sociedad nueva, basada en la justicia, la verdad y el bienestar, una sociedad libre de opresión y discriminación de toda índole, en suma, una nueva edad de oro.

En la magna obra coupa un lugar destacado el Gobierno de Sancho Panza. A pesar de ello, la crítica tradicional no le ha prestado la debida atención tocándolo por encima e interpretándolo parcial y tendenciosamente. La razón de tal actitud la explicaré más adelante.

Ahora bien, sabemos que la idea de convertir al escudero en gobernador de una ínsula - la Insula Barataria - partió de la pareja ducal aragonesa. $\mathrm{Y}$ es que los duques, que habían leído la primera parte del QUIJOTE, sabian que el protagonista había prometido a su escudero entregarle el gobierno de algún condado en la primera ocasión que se le ofreciese. Por ello, invitaron a don Quijote y Sancho Panza a su castillo simulando creer en su calidad de caballero andante y en la de Sancho como su escudero. Allí les prepararon un recibimiento y otras ceremonias al estilo de los libros de caballería con el propósito expreso de matar el tiempo burlándose indecorosamente a costa de cu dignidad humana. Entre sus planes figuraba también la elevación del escudero al gobernador de una ínsula.

La actividad gubernamental de Sancho Panza representa, empero, muy al contrario de lo que los duques y sus paniaguados esperaban, toda una lección de ética política. A manera de gobernantes modernos, se sirve de la primera ocasión que le viene a la mano, para dar a conocer lo que, en la actualidad, llamamos el programa político. Consiste éste en proteger a los labradores, galardonar a los virtuosos, y expulsar a los perezosos y vagamundos.

Expónelo del siguiente modo:

"... Es mi intención limpiar esta ínsula de todo género de inmundicia y de gente vagamunda, holgazana y mal entretenida; porque quiero que sepáis, amigos, que la gente baldía y perezosa es en la república lo mesmo que los zánganos en las colmenas, que se comen la miel que las trabajadoras abejas hacen. Pienso favorecer a los labradores, guardar sus preeminencias a los hidalgos, premiar los virtuosos, y sobre todo, tener respeto a la religión y a la honra de los religiosos.« (II, 49)

Sin embargo, Sancho-gobernador cumple sólo una parte de su programa. Así, impone una cuantiosa multa al fullero jugador que encuentra en su inspección nocturna y destierra por diez años al mirón; condena el vicio del juego y prohibe los garitos. Deporta a la mujer mentirosa y calumniadora, so pena de doscientos azotes si regresa a la ínsula y dictamina en favor del ganadero engañado.

En cambio, durante su gobernación no se nota medida alguna en pro de los hidalgos y sus prerrogativas ni en beneficio de la religión y los religiosos. Hay más aún: en cuanto a los primeros, opino que al hablar de los holgazanes apuntaba asimismo a los hidalgos que, además de otros nobles de mayor rango, no trabajaban y vivían de sus rentas, es decir, del trabajo de los plebeyos, pero a los que por razones obvias no podía mencionar por su nombre. A ello aluden las siguientes palabras de Sancho, el día de su toma de poder: 
»Y yo imagino que en esta ínsula debe haber más dones que piedras; pero basta: Dios me entiende, y podrá ser que si el gobierno me dura cuatro días, yo escardaré estos dones, que por la muchedumbre deben de enfadar como los mosquitos.« (II, 45)

$\mathrm{Y}$ por lo que toca a los religiosos, tampoco hay huella de alguna providencia en su beneficio durante el Gobierno de Sancho Panza. Tan es así, que durante sus actividades de gobernador en su insula no se celebra ninguna ceremonia religiosa; y ello en un país católico, donde no ocurría ningún evento público o privado por insignificante que fuese sin que lo acompañara algún acto religioso. En otras palabras, Sancho-gobernador realiza tan sólo la parte progresista de su programa y deja de cumplir con la parte conservadora, convirtiéndola de tal suerte, en asunto puramente declarativo que, empero, juega el papel de amparo a modo de reiteraciones de ortodoxia que don Quijote se apresura a expresar después de cada una de sus embestidas contra los ministros de Dios, muy al revés de cómo lo hacían y siguen haciéndolo los gobiernos clasistas de cualquier signo, que en sus programas prometen el oro y el moro a las clases mayoritarias, pero de facto llevan a cabo sólo la parte del programa destinado a favorecer a los privilegiados y pudientes cuyos intereses objetivamente representan.

Muéstranlo asimismo, las disposiciones que Sancho adoptó en la economía de su Estado. Así, acabó con los revendedores, liberó la importación de vinos, reguló sus precios y moderó los del calzado; tasó los salarios de los criados y estableció severas sanciones contra los adulteradores del vino y los cantantes de composiciones deshonestas y, por último, dictó varias otras ordenanzas tan buenas que, según afirma Cervantes, hasta hoy se guardan en aquel lugar y se llaman: »Las Constituciones del gran Gobernador Sancho Panza." (II, 51)

Otro campo gubernativo en que nuestro personaje luce su inteligencia y los primores de su sentido natural es el de la administración de justicia. En efecto, los principales asuntos presentados al discernimiento de Sancho, los que más pormenoriza el autor, son los asuntos judiciales. Y Sancho prueba que es un excelente juez. Su justicia es objetiva e imparcial, preocupada exclusivamente por descubrir la verdad de los hechos como único criterio para la aplicación de las leyes, tomando como norte los magníficos consejos que don Quijote le dio antes de partir para el gobierno de la ínsula. He aquí los má importantes:

"Hallen en tí más compasión las lágrimas del pobre, pero no más justicia que las informaciones del rico«;

„Si acaso deblares la vara de la justicia, no sea con el peso de la dádiva sino con el de la misericordia«;

"Nunca te guies por la ley del encaje,* que suele tener mucha cabida con los ignorantes que presumen de agudos«. (II, 42)

Esta nota profundamente humana de la justicia quijotesca, aplicada por Sancho en su gobierno, es reflejo de la orientación humanista del autor. No es fortuito, por ende, el que nuestro gobernador novel tope con casos, cuya solución habría ineludiblemente de ser equivocada, si fuese tomada

* La ley de la arbitrariedad y el soborno 
conforme a los principios de una justicia formal y externa. De tal modo, Cervantes pone en tela de juicio la equidad y la conveniencia de la aplicación, al pie de la letra, de la legislación vigente en su tiempo criticándola desde el punto de vista de una moral auténticamente humana y racional.

En realidad, Sancho resuelve todos los pleitos que se le presentan desde el ángulo de una justicia ética y humana de acuerdo con su conciencia y sentido común, tratando de penetrar en la esencia de tal o cual asunto.

Además, la justicia del escudero es expeditiva y eficaz, ya que procede en el momento y lugar del caso, actúa de inmediato y en consecuencia, muy al contrario de la justicia real que enredaba a los litigantes en un mar de papeles y prolongaba los procedimientos judiciales ad infinitum, dando así la posibilidad a las partes y a los jueces de valerse de métodos y recursos ilícitos, como son los sobornos, los cohechos, la venalidad, etc. No sin razón admiraba Cervantes la justicia musulmana, árabe y turca, que actuaba precisamente de la manera que acabo de mencionar: in situ y de inmediato.

De tal modo, en el caso de las caperuzas denuncia la mala fe de los litigantes, el sastre y su cliente el labrador, por haber llevado éste su desconfianza del sastre, no al temor de que con abuso frecuente se reservase alguna tela sobrante de la necesaria para hacer una caperuza, y sí al exremo desacertado de pedirle que, en lugar de aquella sola le hiciese cinco. A su vez, el sastre muy taimado y burlón, con manifiesta picardía le prometió e hizo lo único que era posible, las cinco caperuzas de juguete que cubrían los dedos de una mano. El fallo de Sancho va dirigido contra la malicia de ambos ordenando el decomiso de las caperuzas a favor de los presos, condenando la maldad fundada en la concepción formal del convenio oral.

Aún mayor sagacidad y dotos de brillante magistrado para la aplicación de la justica demuestra Sancho, cuando le toca elucionar el pleito relativo al préstamo de los diez escudos de oro. Inteligente y perspicaz por naturaleza, colige que el dinero estaba dentro del báculo que el viejo puso en las manos del prestamista, en el preciso momento en que juraba que había devielto los escudos »real y verdaderamente« a quien se los prestó. El prestamista admite la verdad del viejo por ser éste buen cristiano diciendo que es posible se le haya olvidado la devolución del dinero por parte de aquél, pero Sancho se percata con agudeza de la picardía del viejo, cuando éste quita de nuevo el báculo al prestamista, después de jurar y se marcha tranquilamente. Sancho-gobernador, advertido del ardid, manda traer al viejo, le quita el báculo y se lo entrega al prestamista con estas palabras: "Andad con Dios y vais pagado." Ante la duda del prestamista, el escuderogobernador ordena abrir el báculo en cuyo interior encontraron los diez escudos de oro, lo cual causó admiración a sus acompañantes. De esta manera, Cervantes por conducto de su personaje en función de juez rebate la fuerza probatoria del juramento.

Desenmascara también la supuesta inocencia de la mujerzuela que se quejaba de haber sido violada, desterrándola so pena de doscientos azotes si regresara a la insula en estos términos:

„Hermana mia, si el mismo aliento y valor que habéis mostrado para defender esta bolsa lo mostráredes, y aun la mitad menos, para defender vuestro cuerpo, las fuerzas de Hércules no os hicieran fuerza.« (II, 54) 
Pero, donde revela un ánimo jurídico digno de las má altas magistraturas, es en el asunto del puente y la horca que resuelve de la siguiente manera verdaderamente salomónica: "Que deste hombre aquella parte que juró la verdad la dejen pasar y la que dijo mentira la ahorquen«, llegando a la conclusión de que, estando la ley tanto de una como de otra parte de una misma persona, la cual debería en consecuencia ser partida en dos causándole la muerte, se lo tendría que absolver fallando así con un gran sentido humano y de misericordia (II, 51).

Además de las características mencionadas que distinguen la justicia de Sancho-gobernador, hay otra muy importante: En los episodios citados se observa un rasgo común a todos y es, que los sancionados o castigados nunca son enviados a la cárcel, sino que se les requisan las pertenencias objeto del pleito - y se reparten entre los pobres, o se los expulsa de la ínsula o del lugar donde han cometido sus delitos. Esto pone de manifiesto, a su vez, el carácter antirrepresivo y humano de la justicia sanchopancesca.

Ahora bien, si la justicia es un rasgo descollante y trascendental del gobierno del escudero, su carácter popular y democrático lo es igualmente. El personaje que ejerce el poder en la Insula Barataria es un hombre de neta raigambre popular, puesto que es de origen campesino habiendo sido pastor en su niñez y labriego en su madurez. Y Sancho no sólo está perfectamente consciente de ello, sino que se siente orgulloso de serlo conforme al consejo de su amo y guía, don Quijote:

"Haz gala, Sancho, de la humildad de tu linaje, y no te desprecies de decir que vienes de labradores.... (II, 42)

En efecto, cuando se apresta a salir para su gobierno de la Insula Barataria, el duque insiste en que vaya vestido de acuerdo con la investidura del cargo que desempeñará, pero Sancho le responde: „Vístanme... como quisieren; que de cualquier manera que vaya vestido, seré Sancho Panza« (II, 42). Con ello, el escudero-gobernador confirma la validez del refrán popular que reza: „El hábito no hace al monje."

El sello democrático de su gobierno se refleja en las medidas económicas ya apuntadas que favorecen a las capas populares y sus intereses, pues con ellas refrenó los apetitos especuladores de los comerciantes y suprimió algunas limitaciones feudales del comercio y la industria.

Es asimismo democrática la conducta de Sancho-gobernador para con los ciudadanos de su Estado, pues siguiendo también a este respecto los consejos de don Quijote de visitar las cárceles, las carnicerías y las plazas, inspecciona el mercado y los alimentos. Efectúa, además, en persona la ronda de policía de su ínsula durante la cual muestra su bondad y comprensión paternales ante la inexperiencia curiosa de la juventud.

Otra nota sobresaliente del comportamiento del escudero en su gobierno son su extraordinaria honradez y dignidad, virtudes que puede envidiar la mayoría de los jefes de gobierno y de Estado actuales. Efectivamente, su conducta personal es un modelo de integridad y rectitud en todos los aspectos. No obstante estar expuesto al peligro que corren todos los que, de condición humilde, se ven encumbrados de repente de subírseles los humos a la chimenea, no se vuelve ambicioso, sino que hace gala de su humildad: 
»Pues advertid, hermano, ... que yo no tengo don ni en todo mi linaje le ha habido; Sancho me llaman a secas, y Sancho se llamó mi padre y Sancho mi aguielo, y todos fueron Panzas, sin añadiduras de dones ni donas" (II, 45).

recalca el escudero-gobernador al mayordomo, cuando éste le explica el letrero colgado en la pared junto a la silla gobernadoresca en el que se le trata de »don".

También erı orden a lo anterior, Sancho se atiene a pies juntillas al consejo respectivo de don Quijote, cuando le eseña:

»Has de poner los ojos en quien eres, procurando conocerte a tí mismo, que es el más difícil conocimiento que puede imaginarse. Del conocerte saldrá el no hincharte como la rana que quiso igualarse con el buey; que si esto haces, vendrá a ser feos pies de la rueda de tu locura la consideración de haber guardado puercos en tu tierra.« (II, 42)

Por lo visto, don Quijote recuerda a Sancho su estirpe de labrador, por lo que debe actuar como tal, como lo que siempre ha sido en la vida. Pero, al decirle que fue guardador de puercos en su terruño, el ex pastor contesta con aplomo: "que no todos los que gobiernan vienen de casta de reyes $(I I, 42)$.

Otra prueba de la suma honradez con que Sancho gobernó su ínsula la constituye la carta enviada a su señor y mentor don Quijote. Entre las novedades que relata, está la manera en que ha venido administrando los bienes materiales de la Insula Barataria. Escribe así:

"Hasta agora no he tocado derecho ni llevado cohecho, y no puedo pensar en qué va esto; porque aquí me han dicho que los gobernadores que a esta insula suelen venir, antes de entrar en ella, o les han dado o les han prestado los del pueblo muchos dineros, y que ésta es ordinaria usanza de los demás que van a gobiernos, no solamente en éste.« (II, 51)

De la misiva se desprende claramente que el escudero es el único gobernador, que no ha llegado al poder con el propósito de enriquecerse disponiendo de los dineros del pueblo y del Estado, sino todo lo contrario, tiene por meta gobernar en beneficio del pueblo y de toda la entidad actuando con honestidad, justicia y equidad. Obsérvese, además, que a la vez que Sancho está dando testimonio directo de su honradez como gobernante, está poniendo en la picota la administración de los gobernantes de otras ínsulas entiéndase de toda España -.

Y Sancho persevera en subrayar la honradez y desinterés con que administró durante los diez días que duró su gobierno. Así, cuando se dispone a partir para el castillo ducal, ya sobre su rucio, el mayordomo le recuerda que según la usanza de los gobernadores salientes debe dar cuenta de sus actividades gubernamentales. Pero Sancho se niega a hacerlo respondiéndole con energía:

"Nadie me la puede pedir... cuanto más que saliendo yo desnudo, como salgo, no es menester otra señal para dar a entender que he gobernado como un ángel« (II, 53).

habiéndolo probado con creces, pues el único beneficio de su gobierno al abandonarlo fueron medio queso y medio pan, a pesar de haberle ofrecido 
los criados del duque stodo aquello que quisiese para el regalo de su persona y para la comodidad de su viaje.«

Sobre esto, Sancho-gobernador mostró gran pureza de costumbres: humilde y sobrio en el comer y en el vestir, cortés y amable con los buenos y duro con los malos. Tampoco su celo puede ponerse en entredicho. El mismo día que tomó posesión de su ínsula, salió de noche a recorrer sus dominios para sorprender los abusos y necesidades proponiéndose ponerles remedio.

Fue Sancho, además, un gobernador muy digno en un tiempo en que la desvergüenza era la tónica general de los gobernantes corrompidos hasta los tuétanos.** En verdad, al darse cuenta de que su gobierno no fue más que una de tantas burlas descaradas por parte de los altos aristócratas y sus paniaguados, toma la irrevocable decisión de antes renunciar que seguir sirviéndoles de bufón, pese a que el médico Pedro Recio le promete dejarle comer en adelante con abundancia de todo lo que se le antojare.

Así el buen Sancho, en el espacio de unos cuantos días, pasó desde las altas cumbres a una sima profunda, sin ínsula y sin gobierno, víctima de inhumanas y crueles burlas por parte de los lacayos de los duques. Derrocado por aquéllos probó ser hombre tan digno en la desgracia como lo había sido en el poder, conducta prácticamente desconocida por los gobernantes de entonces y por muchos de hoy.

Ahora bien, ¿uién al leer por primera vez el magno libro no piensa que Sancho, investido de gobernador, iba a hacer reír a carcajadas? ¿Quién dejaría de creer que ese improvisado jefe de gobierno no hiciese más locuras en su ínsula que don Quijote en Sierra Morena? Sin embargo, al ejercer Sancho el gobierno con gran inteligencia, acierto, ardor y extrema honradez, su humildad popular vence a la soberbia aristocrática de su señor jurisdiccional, convirtiendo la soez burla de un labrador por parte de aquél en derrota moral y política de su burlador. El mismo mayordomo del duque lo reconoce con las siguientes palabras, cuando acompaña a Sancho en su ronda insular al oírlo exponer su programa político:

"Dice tanto vuesa merced señor gobernador... que estoy admirado de ver que un hombre tan sin letras como vuestra merced, que, a lo que creo, no tiene ninguna, diga tales y tantas cosas llenas de sentencias y de avisos, tan fuera de todo aquello que del ingenio de vuesa merced esperaban los que nos enviaron y los que aquí venimos. Cada día se ven cosas nuevas en el mundo: las burlas se vuelven en veras y los burladores se hallan burlados." (II, 49)

Con ello, Sancho Panza mostró sus idoneidades para gobernar, habiendo administrado a su Barataria con mucha probidad - »desnudo nací, desnudo me hallo, ni pierdo ni gano...., dice a los vasallos del duque al abandonar su gobierno; habiendo juzgado como Licurgo - »el mismo Licurgo, que dio leyes a los lacedemonios, no pudiera dar mejor sentencia«, declara el mayordomo después del dictamen sanchesco sobre el dilema del puente y la horca -; habiendo gobernado como Salomón - "En resolución, él ordenó cosas tan buenas, que hasta hoy se guardan en aquel lugar, y se nombran

:* Cuando Rodrigo Calderón, marqués de Siete Iglesias, uno de los más grandes ladrones de todas las Españas, murió en la horca, el conde de Villa. mediana pudo exclamar: "Con este ladrón muere lo más honrado de España.« 
»Las Constituciones del gran Gobernador Sancho Panza«, - refiere nuestro autor.

Y justamente a este hecho se debe la circunstancia de que los críticos tradicionales, sobre todo los de la patria de Cervantes, hayan dedicado tan poco espacio y atención al Gobierno de Sancho Panza, desvirtuándolo además, ya que para ellos es inconcebible que un labrador pobre, pero inteligente, honesto y trabajador, haya podido convertirse en un gobernante sagaz y burlador de sus señorías, excelencias, eminencias y otras nulidades morales y políticas de aquellos tiempos.

A pesar de sus características progresistas, el régimen de Sancho Panza no es un Estado ideal a modo de la Utopía de Tomás Moro, sino un gobierno democrático de reformas con elementos de utopismo. ¿Podría ser otra cosa? No, porque el autor pese a su gran idealismo fue un hombre de mucha experiencia vital y amplio horizonte, por lo cual se daba perfecta cuenta de que, por una parte, era imposible hacer tabula rasa de todo el desarrollo económico, social y político anterior, y por otra, Sancho recibió las riendas de gobierno de las manos de los señores feudales en son de burla.

El Gobierno de Sancho Panza es, por consiguiente, un régimen reformista y popular influido por las ideas utópico-humanistas de su mentor don Quijote. Tan es así, que el hecho de ser ejercido en una aunque supuesta isla - Insula Barataria - , le confiere cierta similitud con la Utopía del eminente inglés, a la par que con la Ciudad del sol de Tomás Campanella - las dos islas también.

¿En qué consiste, entonces, la lección del Gobierno de Sancho Panza? ¿Tal vez en su fracaso, como opina la gran mayoría de los críticos tradicionales y, sobre todo, conservadores? ¡De ninguna manera!, ya que, por un lado, dicho gobierno fue entregado al escudero e guisa de mofa, conforme lo apunté arriba, y por otro, la existencia más o menos duradera de un gobierno democrático y popular en aquellas condiciones históricas y en el marco del viejo sistema feudal era imposible.

El éxito moral, intelectual y político del escudero Sancho Panza demuestra de modo inconcuso, que la ciencia tan ponderada de gobernar a los hombres y las cosas no es un arcano dependiente de la alcurnia o jerarquía social, sino que es accesible a todos, y para su acertado desempeño se requieren otras cualidades más valiosas que el mero estudio de la política y el conocimiento de las leyes, esto es, sensatez, honradez y sana y justa intención.

Con el fracaso del Sancho Panza de entonces Cervantes señala la falta de premisas históricas para su victoria en aquella época, mientras que con su gran triunfo moral y político brinda a los Sanchos del futuro, como genuinos representantes del pueblo, un ejemplo que les sirva de norte y guía en su camino hacia la completa liberación económica, social y política de la humanidad, hacia el luminoso porvenir de una nueva y definitiva edad de oro.

La tremenda crisis material y moral que agobia al mundo de hoy clama a gritos por un moderno Gobierno de Sancho Panza de alcances universales. 